\title{
Synthesis of a non-stoichiometric pyroxene under ambient pressure
}

\author{
Masato OKUг* and Fumiyuki Marumo \\ Department of Geosystem Sciences, Nihon University, Sakurajosui \\ 3-25-40, Setagaya-ku, Tokyo 156-8550, Japan \\ * Present address: Harima Office, Advanced Materials Laboratory, National \\ Institute for Materials Science, SPring-8 Bll5XU, Koto 1-1-1, \\ Mikaduki-cho, Sayo-gun, Hyogo 679-5148, Japan
}

\begin{abstract}
Crystallization experiments were carried out on powdered glasses having the composition $\mathrm{Di}_{23} \mathrm{Es}_{53} \mathrm{An}_{24}$ at temperatures of $1250,1275,1300,1325$ and $1350^{\circ} \mathrm{C}$. The resulting crystalline phases are clinopyroxenes and a trace of unknown oxide crystals. The pyroxenes grown at 1325 and $1350^{\circ} \mathrm{C}$ are stoichiometric clinopyroxenes rich in $\mathrm{Al}$ and $\mathrm{Fe}$. Those grown at the lower three temperatures are non-stoichiometric clinopyroxenes which are extremely rich in $\mathrm{Al}$ and contain only negligibly small amounts of $\mathrm{Mg}$. Non-stoichiometric clinopyroxenes are shown not to be characteristic products of high pressure conditions.
\end{abstract}

\section{Introduction}

Non-stoichiometric, aluminous clinopyroxenes have been found in eclogites from South African kimberlites (Smyth, 1977 and 1980) and those from Siberian kimberlites (Sobolev et al., 1968), and have attracted much attention from a view point of high pressure silicate mineralogy. Since these non-stoichiometric clinopyroxenes are rimmed with alteration products grown along fine fractures in respective grains of the clinopyroxenes, they are supposed to be stable only under extremely high pressures. Actually Wood and Henderson (1978) showed experimentally that non-stoichiometric clinopyroxenes crystallize from glasses with compositions lying on the joins $\mathrm{CaAl}_{2} \mathrm{SiO}_{6}-\mathrm{SiO}_{2}$ and $\left[\left(\mathrm{CaAl}_{2} \mathrm{SiO}_{6}\right)_{0.7}\left(\mathrm{CaMgSi}_{2} \mathrm{O}_{6}\right)_{0.3}-\mathrm{SiO}_{2}\right.$ at $1300-1450^{\circ} \mathrm{C}$ and $25.0-32.3 \mathrm{kbar}$, and that the degree of non-stoichiometry increases with increasing pressure.

On the other hand, Onuma and Ito (1988) reexamined the phase relations of the join $\mathrm{MgSiO}_{3}(\mathrm{En})-$ $\mathrm{CaAl}_{2} \mathrm{Si}_{2} \mathrm{O}_{8}(\mathrm{An})$ under $1 \mathrm{~atm}$, and found that aluminous protoenstatite appears in the composition

\footnotetext{
M. Okui

F. Marumo, marumo@chs..nihon-u.ac.jp Corresponding author
}

range with lower An contents than 45 mole percent at the relatively lower temperatures, confirming the results reported by Hytonen and Schairer (1961). The chemical composition given by Onuma and Ito for the protoenstatite crystallized at $1300^{\circ} \mathrm{C}$ from the raw material of $\mathrm{En}_{70} \mathrm{An}_{30}$ shows a small degree of cation deficiency from 4 for 6 oxygens, though they did not mention the possibility of non-stoichiometry of this crystal. Esseneite $\mathrm{CaFe}^{3+} \mathrm{AlSiO}_{6}(\mathrm{Es})$ is stoichiometric and known as one of the important members of aluminium-rich clinopyroxenes stable under the ambient pressure. It forms a complete series of clinopyroxene with diopside $\mathrm{CaMgSi}_{2} \mathrm{O}_{6}(\mathrm{Di})$ under $1 \mathrm{~atm}$ (Hijikata and Onuma, 1969).

With the intention to confirm the possibility of crystallization of non-stoichiometric clinopyroxenes under the ambient pressure, the authors conducted crystallization experiments on a glass in the system $\mathrm{Di}$-EsAn under $1 \mathrm{~atm}$ at various temperatures. The system was chosen by taking into consideration the above mentioned experimental facts and chemical compositions of natural non-stoichiometric clinopyroxenes. The present paper describes results of a trial carried out on a raw material with the composition of $\mathrm{Di}_{23} \mathrm{Es}_{53} \mathrm{An}_{24}$. In this study, two types of clinopyroxenes with largely different characters were found to grow according to the heating temperature, of which the products at the lower 
temperatures were non-stoichiometric.

\section{Experimental}

Ten grams of the starting mixture was prepared by weighing reagent grade chemicals of $\mathrm{MgO}, \mathrm{Al}_{2} \mathrm{O}_{3}, \mathrm{Fe}_{2} \mathrm{O}_{3}$ and $\mathrm{SiO}_{2}$, and $\mathrm{CaCO}_{3}$ for alkali analysis in the ratios to give the average composition of $\mathrm{Di}_{23} \mathrm{Es}_{53} \mathrm{An}_{24}$ (i.e. $\mathrm{Al}_{2} \mathrm{O}_{3}$ 20.80, $\mathrm{CaO} 22.66, \mathrm{Fe}_{2} \mathrm{O}_{3}$ 17.10, $\mathrm{MgO} 3.75, \mathrm{SiO}_{2} 35.69$ wt\%). The chemicals were wet-mixed with ethanol and put in a platinum envelope. Then, the mixture was heated to $1400^{\circ} \mathrm{C}$ in an $\mathrm{SiC}$ electric furnace and kept at this temperature for 2 hours. The melt was dropped into ice-water together with the platinum envelope to get a glass. The obtained glass was pulverized and wetmixed again with ethanol. The glass powder was melted at $1400^{\circ} \mathrm{C}$, and the vitrifying procedure was repeated. Then, the product was pulverized, well mixed and used for the starting materials in the subsequent crystallization experiment. The chemical composition of the starting material was checked by analyzing a part of the glass with electron probe microanalyzer (JEOL JSM5400S/LINK CX2000S), and found it to have the aimed composition within the experimental errors of the present study.

The pulverized starting material was separated into five parts and put in platinum capsules. They were heated at $1350,1325,1300,1275$ and $1250^{\circ} \mathrm{C}$ for 90 hours in air, respectively, and then dropped into ice-water to be quenched. The temperature in the furnace was measured with a $\mathrm{Pt}-\mathrm{Rh} 13 \mathrm{Pt}$ thermocouple. The stability of temperature was better than $\pm 10^{\circ} \mathrm{C}$ in the furnace around the specimens.

The obtained materials were observed under a polarized optical microscope by making thin sections, and examined with powder $\mathrm{X}$-ray diffractometry and electron probe microanalysis. Single-crystal $\mathrm{X}$-ray diffraction experiments were carried out on some crystalline products to reveal detailed characters of the crystals.

\section{Results}

All the $\mathrm{X}$-ray powder diffraction patterns of the products showed only the peaks of clinopyroxenes and broard haloes from glasses. However, unknown oxide crystals were found sometimes in the products with

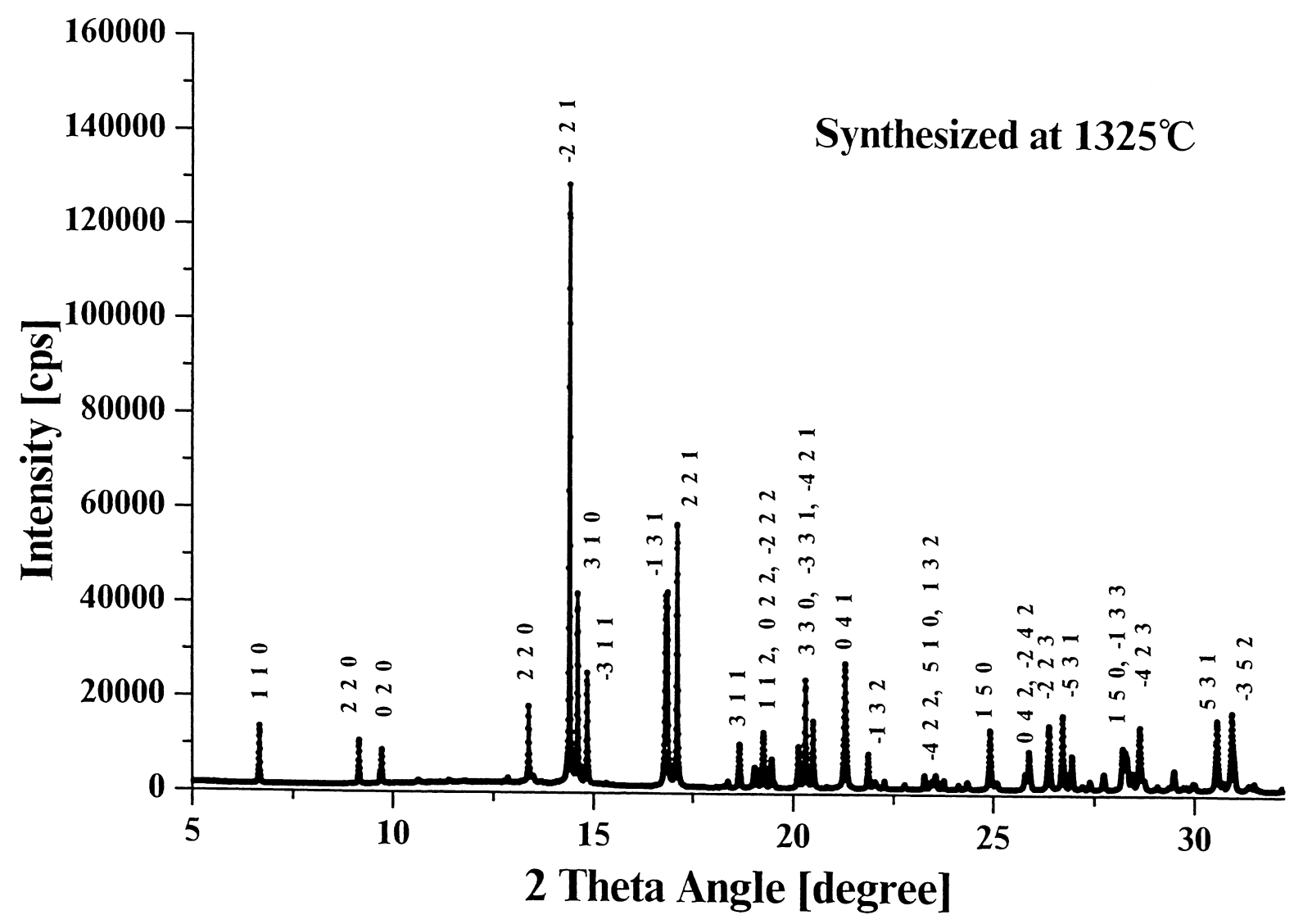

Figure 1. X-ray powder diffraction pattern of the product obtained at $1325^{\circ} \mathrm{C}$ recorded with synchrotron radiations of $0.749817(3) \AA$. 


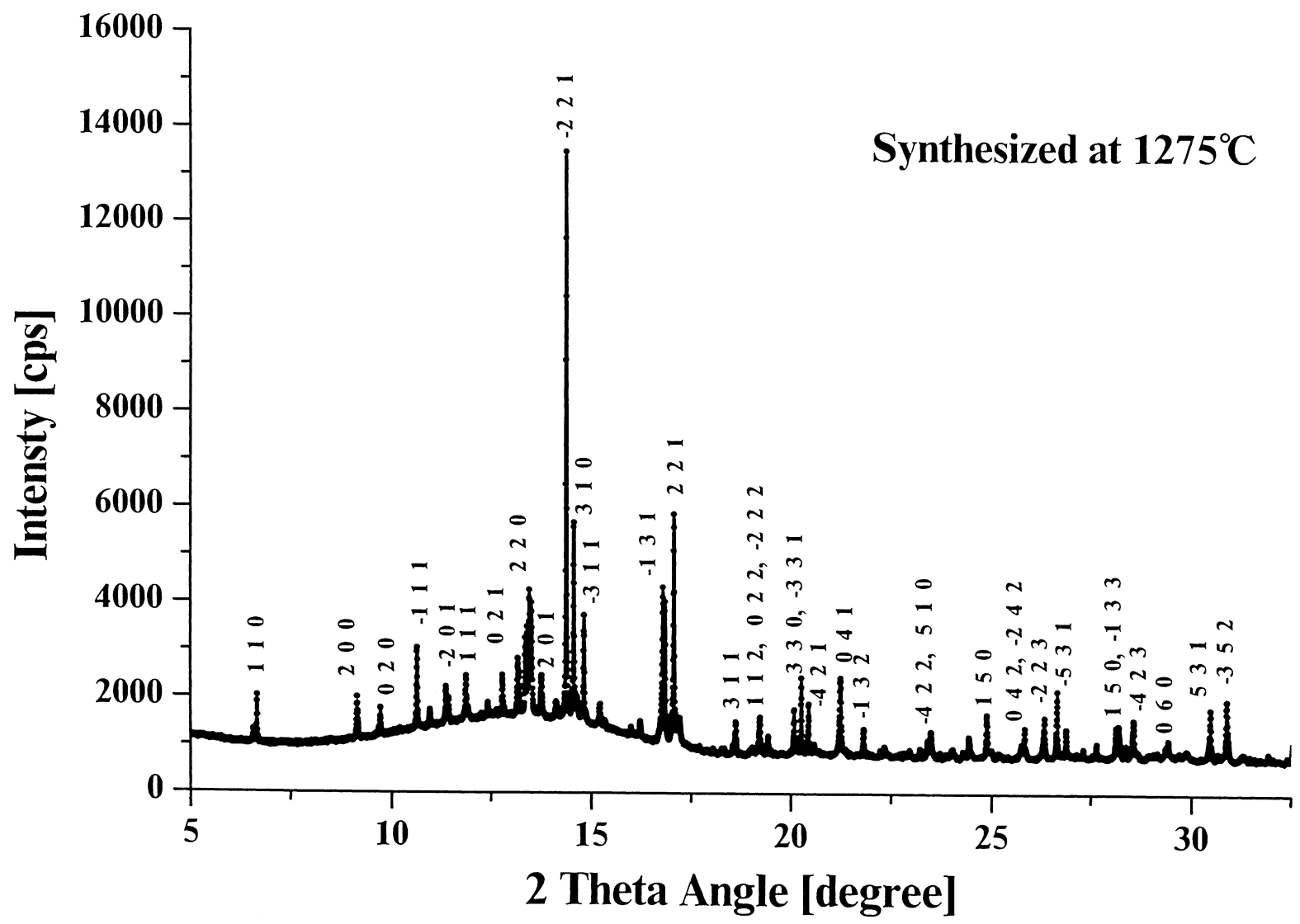

Figure 2. X-ray powderdiffraction pattern of the product obtained at $1275^{\circ} \mathrm{C}$ recorded with synchrotron radiations of $0.749817(3) \AA$.

electron microscopic observations. These crystals were so small that they could not be recognized under the optical microscope. Figures 1 and 2 show the diffraction patterns of the products at 1325 and $1275^{\circ} \mathrm{C}$ recorded on a Rigaku SOR-PD1 diffractometer at SPring-8 Bl15XU WEBRAM with radiations of $0.749817(3) \AA$ in wavelength. Indices are given for the stronger reflections.

Crystal sizes of clinopyroxenes depend on the heating temperature: higher the temperature, larger the maximum size of grown crystals. The maximum sizes of the obtained crystals are about $40 \times 40 \times 100 \mu \mathrm{m}$ and $10 \times 10 \times 40 \mu \mathrm{m}$ in the heating temperatures of $1350^{\circ} \mathrm{C}$ and $1250^{\circ} \mathrm{C}$, respectively. The pyroxenes obtained at $1350^{\circ} \mathrm{C}$ and $1325^{\circ} \mathrm{C}$ are brownish green, while those obtained at the lower temperatures are pale green. Since apparent colours are dependent upon sizes of crystals, it is not clear if the tint difference is intrinsic or not. The crystals show distinct cleavages parallel to the elongated direction as usually observed in pyroxenes, and have higher refractive indices than the surrounding glasses.

Chemical analyses were performed on crystals in the thin sections used for microscopic observations with the electron probe microanalyzer. The results are shown in Table 1. The values are means of analyses carried out on several crystals in the respective products at different temperatures. As to the product at $1275^{\circ} \mathrm{C}$, only one crysal was available for the analysis in the thin section. The numerals in parentheses are the standard deviations expressed in the final digit. No compositional differences were observed between the center and rim of the analyzed crystals. Numbers of atoms for 6 oxygens were derived from the obtained compositions, and given in Table 2. The obtained pyroxenes were confirmed to be $\mathrm{C} 2 / \mathrm{c}$ clinopyroxenes by taking Weissenberg photographs on several single-crystals.

\section{Discussion}

Distinct differences are observed between clinopyroxenes synthesized at the higher two temperatures (1350 and $1325^{\circ} \mathrm{C}$ ) and those synthesized at the lower three temperatures in chemical compositions. The clinopyroxenes grown at the higher two temperatures are stoichiometric 
Table 1. Chemical compositions of clinopyroxenes obtained from $\mathrm{Di}_{23} \mathrm{Es}_{53} \mathrm{An}_{24}$ glass at various temperatures

\begin{tabular}{llllll}
\hline & $1250^{\circ} \mathrm{C}$ & $1275^{\circ} \mathrm{C}$ & $1300^{\circ} \mathrm{C}$ & $1325^{\circ} \mathrm{C}$ & $1350^{\circ} \mathrm{C}$ \\
\hline $\mathrm{SiO}_{2}$ & $43.4(0)$ & 44.2 & $43.5(7)$ & $36.3(4)$ & $45.4(3)$ \\
$\mathrm{Al}_{2} \mathrm{O}_{3}$ & $30.2(10)$ & 29.9 & $31.5(13)$ & $9.3(2)$ & $11.3(3)$ \\
$\mathrm{Fe}_{2} \mathrm{O}_{3}$ & $7.1(11)$ & 6.4 & $5.4(16)$ & $26.4(10)$ & $16.3(6)$ \\
$\mathrm{MgO}$ & $0.6(3)$ & 0.4 & $0.4(3)$ & $6.8(4)$ & $3.3(1)$ \\
$\mathrm{CaO}$ & $19.4(3)$ & 19.5 & $19.6(3)$ & $23.7(1)$ & $23.7(3)$ \\
Total & 100.7 & 100.4 & 100.4 & 102.5 & 100.0 \\
\hline
\end{tabular}

The values for $1250,1300,1325$ and $1350^{\circ} \mathrm{C}$ are the averages of measurements on $2,12,3$ and 6 crystals, respectively. The standard deviations based on the final digit are given in parentheses.

Table 2. The number of atom per six oxygens in pyroxenes obtained at various temperatures

\begin{tabular}{llllll}
\hline & $1250^{\circ} \mathrm{C}$ & $1275^{\circ} \mathrm{C}$ & $1300^{\circ} \mathrm{C}$ & $1325^{\circ} \mathrm{C}$ & $1350^{\circ} \mathrm{C}$ \\
\hline $\mathrm{Si}$ & $1.53(0)$ & 1.56 & $1.55(2)$ & $1.41(1)$ & $1.78(1)$ \\
$\mathrm{Al}$ & $1.26(4)$ & 1.24 & $1.32(5)$ & $0.43(1)$ & $0.52(2)$ \\
$\mathrm{Fe}^{3+}$ & $0.19(3)$ & 0.17 & $0.15(4)$ & $0.77(3)$ & $0.48(2)$ \\
$\mathrm{Mg}$ & $0.03(2)$ & 0.02 & $0.02(1)$ & $0.39(2)$ & $0.19(1)$ \\
$\mathrm{Ca}$ & $0.73(1)$ & 0.74 & $0.75(1)$ & $0.99(1)$ & $0.99(1)$ \\
Total & 3.74 & 3.73 & 3.79 & 3.99 & 3.96 \\
\hline
\end{tabular}

Standard deviations based on the final digit are given the parentheses for the values obtained from measurements on plural specimens.

within the experimental errors, whereas those grown at the lower three temperatures are evidently non-stoichiometric as seen in Table 2. In addition, there are marked differences in the atomic ratios of constituent elements between the stoichiometric clinopyroxenes (henceforth abbreviated as Sto-CPx) and the non-stoichiometric clinopyroxenes (abbreviated as Non-Sto$\mathrm{Cx})$. The Sto-CPx contains practically one $\mathrm{Ca}$ atom for six oxygens, while the Non-Sto-Cpx has much lower $\mathrm{Ca}$ contents: around 0.75 for six oxygens. The lower $\mathrm{Ca}$ contents in the Non-Sto-CPx are supposed to have a close relation with the non-stoichiometry, since the vacancies reside mainly at the M2 sites according to previous studies (Wood and Henderson, 1978; Smyth, 1980; Oberti and Caporuscio, 1991; Okui et al., 1998).

A significant feature of Non-Sto-CPx exists in its negligibly small content of $\mathrm{Mg}$. In contrast, the StoCPx contains 0.2 to $0.4 \mathrm{Mg}$ atoms for 6 oxygens. The Non-Sto-Cpx is extremely aluminium rich. Similar features are recognized in natural Non-Sto-CPx and those synthesized under high pressures. On the other hand, the Sto-CPx obtained in the present experiments are richer in Fe than the Non-Sto-CPx. The chemical composition of Sto-CPx obtained at $1325^{\circ} \mathrm{C}$ indicates occupation of ferric ions at the $\mathrm{T}$ sites. The authors carried out structure refinement of Sto-CPx synthesized from a raw material with the same chemical composition as those used in the present study, but with somewhat different heat treatment from the present ones, namely with a slow cooling from 1400 to $1000^{\circ} \mathrm{C}$ (Okui et al., 1997). The refinement indicates that a part of ferric ions occupy the $\mathrm{T}$ sites, though the crystal contains enough amounts of $\mathrm{Si}$ and $\mathrm{Al}$ atoms to fill the $\mathrm{T}$ sites. The result of chemical analysis on Sto-CPx synthesized at $1325^{\circ} \mathrm{C}$ should be reasonable in view of this fact, though the total of $\mathrm{Si}$ and $\mathrm{Al}$ is insufficient to fill the T sites. Similarly, a part of ferric ions are also expected to occupy $\mathrm{T}$ sites in Sto-CPx obtained at $1350^{\circ} \mathrm{C}$, though the crystals contain enough $\mathrm{Al}$ to fill the $\mathrm{T}$ sites with $\mathrm{Si}$. The differences are negligibly small between chemical compositions of Non-Sto-CPx crystals synthesized at different temperatures, whereas a distinct difference is observed between the chemical compositions of the StoCPx crystals synthesized at 1350 and $1325^{\circ} \mathrm{C}$.

With the present study, Non-Sto-CPx is shown not to be a unique product of high pressure conditions as 
previously supposed. The mineral can be grown even under the ambient pressure according to the chemical composition of raw material and the thermal condition. It is also very interesting that two types of $\mathrm{CPx}$ with largely different characters are crystallized from the identical raw material depending upon the growing temperature. In the present case, the temperature boudary lies between $1325^{\circ} \mathrm{C}$ and $1300^{\circ} \mathrm{C}$.

\section{Acknowledgements}

The authors are grateful to late Dr. H. Sawada for his valuable discussions and advices. The authors also wish to thank Dr. Atsushi Nisawa and all other staffs of SPring-8 BL15XU for their help in the diffraction experiments with synchrotron radiations. Financial support from the Ministry of Education, Science, Sports and Culture (Grant-in-Aid for Scientific Research, No. 10640471) are acknowledged.

\section{References}

Hijikata, K. and Onuma, K. (1969) Phase equilibria of the system $\mathrm{CaMgSi}_{2} \mathrm{O}_{6}-\mathrm{CaFe}^{3+} \mathrm{AlSiO}_{6}$ in air. The Journal of The Japanese Association of Mineralogists, Petrologists and Economic Geologists, 62, 209-217.

Hytonen, K. and Schairer, J.F. (1961) The plane enstatiteanorthite-diopside and its relation to basalts. Carnegie Institute of Washington Year Book, 60, 125-141.
Oberti, R. and Caporuscio, F.A. (1991) Crystal chemistry of clinopyroxenes from mantle eclogites: A study of the key role of M2 site population by means of crystal-structure refinement. American Mineralogist, 76, 1141-1152.

Okui, M., Marumo, F., Sawada, H., Ueki, M. and Ishizawa, N. (1997) Site confirmation of $\mathrm{Fe}^{3+}$ in a synthetic ferrian, aluminian diopside with an application of $\mathrm{X}$-ray anomalous dispersion. Mineralogical Journal, 19, 165-172.

Okui, M., Sawada, H. and Marumo, F. (1998) Structure refinement of a non-stoichiometric pyroxene synthesized under ambient pressure. Physics and Chemistry of Minerals, $25,318-322$.

Onuma, K. and Ito, H. (1988) Re-examination of the join $\mathrm{MgSiO}_{3}-\mathrm{CaAl}_{2} \mathrm{Si}_{2} \mathrm{O}_{8}$. The Science Reports of the Tohoku University, Series III, XVII, No. 1, 129-135.

Smyth, J.R. (1977) Peraluminous omphacite: cation vacancies in mantle-derived pyroxene (abstract). Transactions of American Geophysical Union, 58, 523.

Smyth, J.R. (1980) Cation vacancies and the crystal chemistry of breakdown reactions in kimberlitic omphacites. American Mineralogist, 65, 1185-1191.

Sovolev, N.V.Jr., Kuznetsova, I.K. and Zyuzin, N.I. (1968) The petrology of grospydite xenoliths from Zagodochnaya kimberlite pipe in Yakutia. Journal of Petrology, 9, 253280.

Wood, B.J. and Henderson, C.M.B. (1978) Compositions and unit-cell parameters of synthetic non-stoichiometric tschermakitic clinopyroxenes. American Mineralogist, $63,66-72$.

Manuscript received; 19 March, 2001

Manuscript accepted; 9 July, 2001 